Code, is justified if performed by a physician complying with specified due care requirements. A review committee assesses in every case whether physician-assisted dying has been carried out in accordance with these requirements. If there is reason for doubt, the case is handed over to the Public Prosecutor who judges whether there are grounds for prosecution.

One of the current challenges in the Netherlands is the significance of an advance directive requesting euthanasia. Section 2 (2) of the Wtl allows physicians to carry out euthanasia on patients lacking mental capacity based on an advance directive requesting euthanasia drawn up at a time the patient was still competent. The due care requirements apply 'to the extent allowed for by the actual situation'. Uncertainty exists about the interpretation of the wording.

This study examines the legal status and practice of advance directives requesting euthanasia, focusing on the question how the due care requirements can be met in case of advance directives concerning late stage dementia patients. The legislative history and case law offers advice how to assess the due care requirements but do not seem to provide enough guidance for a careful and practical application of the advance directive. The legal position of the advance directive requesting euthanasia is complex and in need of assessment.

\section{P15 TALKING ABOUT HEALTHCARE DECISIONS WITH END-OF-LIFE PATIENTS: WHAT DO NURSES FEEL?}

${ }^{1}$ Nani Granero-Moya*, ${ }^{2}$ Concepción Gómez Cadenas, ${ }^{3}$ Laura Parra Anguita, ${ }^{4}$ Antonio J Ramos-Morcillo, ${ }^{5}$ Antonio Frías Osuna. 'Distrito sanitario Jaén Nordeste, ZBS Baeza. Universidad de Jaen, Spain; ${ }^{2}$ Centro de Salud Monreal del Campo, EUE Teruel, Spain; ${ }^{3}$ Universidad de Jaen, Spain; ${ }^{4}$ Universidad de Murcia, Spain

\subsection{6/spcare-2019-ACPICONGRESSABS.103}

Objective To know the emotions of community nurses when they talk to end-of-life patients about health care decisions for their future

Design: Qualitative methodology.

Location: Basic health zone. Jaén.Spain

Participants: Community nurses who care for people at the end of life.

Main interventions Fourteen recorded interviews after informed consent. Analysis: transcription of speeches, coding of texts and grouping in categories.

Results Nurses' emotions include discouragement, worry, sadness, anxiety, insecurity, bewilderment, anger, compassion or frustration.These affective phenomena appear after negatives experiences such as deception or difficulty in certain situations, lack of resources to face dialogical processes of health decisions planning or acknowledging the other's suffering. The presence of such emotions leads the professional to adopt avoidance attitudes to elude a reality that causes them emotional distress. There are also participants who feel tranquility, respect, security, satisfaction or affection. These emotions are related to positive experiences, which generate a proactive attitude in the professional and promote actions that improve the quality in care at the end of life.

Conclusion Knowing the present emotions in the clinical relationship can help the professional. When the professional manages properly his/her emotions there is a better healthcare provision at the end of life. It is necessary to improve nurses' emotional competencies through affective education.

\section{P18 \\ ADVANCE CARE PLANNING (ACP) DISCUSSIONS: WHAT DO THEY REALLY COST?}

${ }^{1} \mathrm{M}$ Nesari ${ }^{*},{ }^{2} \mathrm{M}$ Douglas, ${ }^{1} \mathrm{~J}$ Xiao, ${ }^{1} \mathrm{P}$ Biondo, ${ }^{1} \mathrm{~N}$ Hagen, ${ }^{1} \mathrm{~J}$ Simon, ${ }^{1} \mathrm{~K}$ Fassbender. ${ }^{1}$ University of Alberta, Edmonton, Canada; ${ }^{2}$ Faculty of Medicine and Dentistry, University of Alberta, Edmonton, Canada

\subsection{6/spcare-2019-ACPICONGRESSABS.104}

Background Understanding both costs and consequences of ACP programs is important. Available economic analysis have typically reported the consequences but not the prevalence, frequency, duration and with whom ACP discussions take place.

Methods We conducted an economic analysis of ACP discussions alongside a trial evaluating ACP videos, across three clinical settings (cancer, heart and kidney disease) and 18 sites in Alberta, Canada. We administered a Health Services Inventory monthly for three months. Participants were asked to recall ACP discussions with professionals from healthcare, legal, financial and spiritual sectors.

Results 241 participants $(36.1 \%$ female; average age, $66 \pm$ 12.2 years) were interviewed at baseline with $95.0 \%$ followup over the three months. Participants across cancer $(n=36)$, heart disease $(n=24)$, and renal disease $(n=40)$ settings had in total 100 ACP discussions with professionals from healthcare $(n=58)$, spiritual $(n=14)$, legal $(n=19)$ and financial $(n=9)$ sectors. The discussions averaged 20.4 minutes and resulted in completion of 16 Goals of Care Designation GCDs, 14 Personal Directives and 9 financial documents. Discussions mostly occurred outside home $(\mathrm{n}=82,80.4 \%)$ and patients were almost always accompanied by a family member/friend $(n=99$, 97\%).

Conclusion(s) Compensating professionals to engage in ACP discussions represents a substantial segment of ACP program cost. Patients and their family/friends also incur costs travelling to and taking time for appointments. Assessing cost-effectiveness of ACP requires program costs in addition to consequences. Patient engagement likewise benefits from understanding the nature and personal costs of these discussions. These data may help professionals advocate for commensurate compensation

\section{P19 $\quad$ THE USE OF ADVANCE CARE PLANS IN PATIENTS ADMITTED TO A PUBLIC HOSPITAL}

J Goodwin*, D Speelberg, K Grundy. Canterbury Initiative, Christchurch, New Zealand

\subsection{6/spcare-2019-ACPICONGRESSABS. 105}

Background This study followed the clinical history of a cohort of patients with a published Advance Care Plan (ACPlan) and examined the influence of the patient's clinical and demographic characteristics on the content of the ACPlan. The concordance between the instructions in the ACPlan and the care received during admissions and/or end of life care in a public hospital was also investigated.

Methods 149 patients with a published ACPlans between 10/ 09/2014 and 31/09/2017, and an admission to Christchurch Hospital within that timeframe, were randomly selected from the ACP database $(n=1939)$. The electronic and written clinical records of each hospital admission of the patients $(n=411)$ were reviewed to record demographic characteristic and assess competence. For those who lacked capacity, further review 
was undertaken to determine treatment given and concordance with the ACPlan.

Results Median age was 78 years. 57\% were female, $43 \%$ male. The study showed a $98.3 \%$ concordance rate regarding the Goal of Care, and $85.7 \%$ concordance rate regarding the specific treatment preferences. A Do-not-attempt-CPR form was in place in $60.2 \%$ of the records of patients who did not want to receive CPR. Of the patients who died during the study period $(n=55) 37.5 \%$ died in their preferred location, while $18.8 \%$ did not state a place of death preference.

Conclusion(s) Although the study population was limited, the results add to the evidence that ACPlans encourage the wishes of hospitalised patients to be recognised and used to guide care.

\section{P20 QUALITY REVIEW PROCESS FOR ELECTRONIC ADVANCE CARE PLANS IN CANTERBURY, NEW ZEALAND}

J Goodwin*, K Grundy, E McLardy. Canterbury Initiative, Christchurch, New Zealand

\subsection{6/spcare-2019-ACPICONGRESSABS.106}

Background An Advance Care Plan (ACPlan) that is ambiguous, contradictory or difficult to interpret can undermine confidence in the ACP process, lead clinicians to question the value of ACP and reduce the likelihood a person's ACP wishes will be honoured.

In Canterbury, a quality process has been developed to ensure ACPlans published to the electronic medical record (EMR) are clinically interpretable and any advance directives (AD) contained within the document meets NZs criteria for validity.

Methods a two-step process has been developed

Step 1 - Administration review to ensure the plan has been entered onto the EMR; the signed scanned copy matches the EMR version; there are two signatures - that of the person creating the ACPlan and the health care professional (HCP) supporting them.

Step 2 - Clinical review to ensure the content of the ACPlan is consistent with any ADs contained in the document and the plan is clinically interpretable.

If an ACPlan does not meet the quality parameters, it is returned for review and amendment. This process enables the ACP team to engage with the HCP leading the process, provide individual feedback and support them to improve the quality of plans submitted in the future.

Results Numbers of ACPlans published continue to grow (2014 $\mathrm{n}=118 ; 2015 \mathrm{n}=354 ; 2016 \mathrm{n}=519 ; 2017 \mathrm{n}=772$ ). While the percentage of plans requiring support from the ACP team to meet publishable criteria is falling $(2014=31 \%$; $2015=32 \% ; 2016=27 \% ; 2017=20 \%$ ).

Conclusion(s) The quality review process established in Canterbury supports the creation of clinically interpretable ACPlans.

\section{P21 ADVANCE CARE PLANNING FACILITATOR TRAINING FOR MEDICAL STUDENTS: MORE THAN A DROP IN THE OCEAN}

${ }^{1} \mathrm{~K}$ Götze ${ }^{*}{ }^{2} \mathrm{~J}$ In der Schmitten, ${ }^{1} \mathrm{~A}$ Fuchs. ${ }^{1}$ Heinrich-Heine University, Düsseldorf, Germany; ${ }^{2}$ Institute for general medicine, Düsseldorf, Germany

10.1136/spcare-2019-ACPICONGRESSABS. 107
Background Healthcare professionals (HCP) often feel insecure and therefore hesitate to start ACP conversations with patients. And patients often feel reluctant to initiate ACP-conversations. Trying to discontinue this vicious circle we developed an elective ACP course for medical students.

Methods The course was developed on the base of the German facilitator-curriculum, which was revised in 2017 to include intensive role-play supported by the use of standardized-patients (SP). We adapted the facilitator curriculum to the students' experience and early stage of medical training. Course preparation comprised a letter of motivation and $10 \mathrm{CME}$ questions referring to an ACP journal paper. The course is divided into 2 parts, each lasting 32 hours and including 10 hours of SP-training in groups of 2 or 3 .

Results In August 2018, 7 students joined part 1 of the new ACP-course. All 7 students were in their 2 nd year of medical training, the age range was $20-42$ yrs, 3 were female. 5 happened to have a Muslim background which added an unexpected cultural component to the course. 4 had worked in other disciplines in healthcare before. Their motivation to participate ranged from traumatizing personal experiences to practical reasons. Their attitudes towards patient-centeredness and ACP-facilitation strongly changed from a traditional-paternalistic towards an autonomy-oriented view. At the end, student performance varied from moderate to very good.

Conclusion(s) Discussing legal and ethical basics of ACP conversations, and practicing ACP with SP, were judged by the students as highly relevant, both personally and professionally.

\section{P22 INTEGRATION OF ACP INTO PRIMARY CARE. THE CANTERBURY EXPERIENCE}

J Goodwin*, E McLardy, K Grundy. Canterbury Initiative, Christchurch, New Zealand

\subsection{6/spcare-2019-ACPICONGRESSABS. 108}

Background In 2013 a project was developed for the provision of formal Advance Care Planning (ACP) processes in the Canterbury Health System.

A key component of the project was facilitating general practice to engage with and support patients to undertake ACP conversations and develop electronic advance care plans (eACPlans).

Methods Integrating ACP into the primary care system in Canterbury required a multifaceted, cross system approach, with each component supporting and enhancing the other.

Practice engagement and education including practice visits, phone support, ACP processes on the clinical website, presentations, training, one-to-one support/mentoring

Consumer engagement and education including community presentations, radio interviews, articles in local publications, a consumer website \& community ACP champions. Increasing the community's knowledge and desire to create plans, has been the impetus for many practices to engage with ACP.

Systems and processes including electronic sharing of eACPlans, a subsidy to support practice teams adopt ACP and dedicated ACP facilitators \& administrators to support the process.

Quality loop plans are reviewed to ensure patient's wishes are clinically interpretable and clinicians are confident to use plans to guide care. Plans that do not meet the quality 